\title{
Individual and Society within the Post Modern Ethos
}

\author{
SEDRATA Yasser \\ Biskra University, Algeria
}

\begin{abstract}
This paper will address the notion of the incommensurable, subjective, and the relativistic tendency of the Post Modern epistemology in judging the social, cognitive, and the political identifiabilities. The legacy of Michelle Foucault and Jack Derrida, which came as a reaction against the entire Enlightenment project, has undermined which was considered as the basic referential testimonio that organize and stratify the epistemological patterns of thought, and gave rise to a new paradigmatic reciprocity that emphasized valuelessness, absence of univocity, and irrationality, in addition, to social, ethnic constructability, and partial subjective finality in holding truth judgmentality. In this paper, the researcher will territorialize the problematic within the triangle of: epistemological relativity, social egalitarianism, and the system of valuelessness that postmodern system calls for. In the light of the latter, we will try to raise the question that under the pretext of incommensurable objective truth, how can we establish an interrelated egalitarian cross cultural atmosphere that insures equal representation for all constituents of the society without conscious or unconscious ideological tendencies that Foucault and Leotard have argued about? Also, how the valueless system is manifested in social relationships, and to which extent is it considered legitimate reactionary counter-argument that is meant to perpetuate certain streamline of thought? The researcher will adopt an investigative qualitative method that analyses the aforementioned in the light of postmodern philosophy.
\end{abstract}

Keywords: Egalitarianism, Epistemology, Relativism, Subjective, System, Valueless. 